\title{
PROTOCOLOS DE CUIDADOS FRENTE A DOENÇAS DECORRENTES DE BIOTERRORISMO
}

Ercole FF, Costa RS. Protocolos de cuidados frente a doenças decorrentes de bioterrorismo. Rev Latino-am Enfermagem 2003 julho-agosto; 11(4):516-24.

Epidemias conseqüentes a ações de bioterrorismo e medidas de prevenção e controle dessas infecções têm preocupado não só os governantes, mas, também, profissionais de saúde em geral. Profissionais de saúde devem reconhecer precocemente essas doenças. Informações e atualizações sobre o tema fazem-se necessárias. Este artigo traz uma revisão de literatura realizada na base de dados MEDLINE e LILACS, livros e informações online (referentes ao período de 1993 a 2001) sobre os aspectos epidemiológicos das principais doenças decorrentes do bioterrorismo e as recomendações de cuidados para 0 controle de infecção e minimização dos riscos ocupacionais. Os profissionais da enfermagem, que prestam assistência direta a pacientes, devem estar preparados para atender casos isolados ou aqueles ocorridos em epidemias.

DESCRITORES: bioterrorismo; infecção/prevenção e controle; enfermagem

\section{CARE PROTOCOL FOR PRECAUTIONS AGAINST DISEASES CAUSED BY BIOTERRORIST ACTIONS}

Epidemics due to bioterrorist actions and prevention and control measures of these infections have been worrying not only the policy makers but also health professionals in general. Health professionals have to recognize these diseases earlier. Information and updated studies about the issue are needed. This study is a literature review in the MEDLINE and LILACS databases, books and online information (from 1993 to 2001) about epidemic aspects of the main diseases due to bioterrorist actions and care recommendations for infection control and occupational risk minimization. Healthcare professionals, who assist patients directly, should be prepared to assist patients who become ill in isolated or epidemic situations.

DESCRIPTORS: bioterrorism; infection/control and prevention; nursing

\section{PROTOCOLOS DE CUIDADOS FRENTE A LAS ENFERMEDADES DERIVADAS DEL BIOTERRORISMO}

Las epidemias en consecuencia de las acciones bioterroristas y las medidas de prevención y control de estas infecciones son una preocupación no solamente de los gobernantes, sino también de los profesionales de salud en general. Los profesionales de salud deben reconocer con antelación estas enfermedades. Las informaciones y las actualizaciones sobre el tema, son fundamentales. El artículo trae una revisión de literatura realizada con base en datos MEDLINE y LILACS, libros e informaciones online (alusivo al periodo de 1993 a 2001) sobre los aspectos epidemiológicos de las principales enfermedades del bioterrorismo y las recomendaciones de los cuidados para el control de estas infecciones, además de minimizar los riesgos ocupacionales. Los profesionales de enfermería, que prestan atención directa al enfermo, deben estar preparados para atender los casos aislados o aquellos ocurridos en epidemias.

DESCRIPTORES: bioterrorismo; infección/prevención y control; enfermería

\footnotetext{
${ }^{1}$ Enfermeira, Mestre em Enfermagem pela Escola de Enfermagem da Universidade Federal de Minas Gerais, Doutoranda do Programa de PósGraduação do Departamento de Parasitologia do ICB/Universidade Federal de Minas Gerais (Área de concentração: Epidemiologia), e-mail: flaviaercole@aol.com, ${ }^{2}$ Enfermeira, Mestre em Enfermagem pela Escola de Enfermagem da Universidade Federal de Minas Gerais, Enfermeira do Núcleo de Cirurgia Ambulatorial do PAM Sagrada Família, Prefeitura de Belo Horizonte, e-mail: rbm@mkm.com.br
} 
INTRODUÇÃO

$\boldsymbol{H}_{\text {istoricamente, a guerra biológica vem ocorrendo }}$ desde a Idade Média. Nos recentes anos, a utilização de agentes biológicos em atentados terroristas tem sido, até então, infreqüente. Porém, tendo em vista os fatos ocorridos nos Estados Unidos, em 11 de setembro de 2001, consideramos relevante a abordagem desse tema, para subsidiar a prática dos profissionais de saúde, particularmente dos enfermeiros. $O$ enfermeiro e equipe, encarregados de prestarem assistência direta a pacientes hospitalizados, devem preparar-se para o reconhecimento precoce e atendimento aos casos isolados, ou mesmo aqueles ocorridos em epidemias provocadas por ataques intencionais, onde são utilizados agentes biológicos.

\section{OBJETIVOS}

Este artigo tem como propósito revisar os aspectos epidemiológicos das principais doenças decorrentes de uma guerra biológica, seus agentes infecciosos e as precauções adotadas nos hospitais para o controle dessas infecções, gerando, assim, conhecimento atualizado sobre o tema.

\section{METODOLOGIA}

O levantamento de informações atualizadas sobre o tema foi realizado sob a forma de revisão de literatura, utilizando-se artigos da base de dados Medline e Lilacs, livros e informações online do John Hopkins Center for Civilian Biodefense Studies e do Centers for Disease Control and Prevention (CDC-P), em Atlanta, EUA, no período de 1993 a 2001. No artigo foram abordados o bioterrorismo, o reconhecimento das principais doenças e algumas práticas de controle dessas infecções.

\section{RESULTADOS}

O bioterrorismo

Desde a Segunda Guerra Mundial, países como Japão, EUA e União Soviética manipulam, produzem e armazenam, para fins militares, agentes biológicos e químicos, com capacidade substancial para causar doença e morte ${ }^{(1)}$. No final da década de setenta, os EUA destruíram seu arsenal biológico. Entretanto, países como a União Soviética, Iraque e Japão mantêm programas de desenvolvimento e produção de armas biológicas, em sua grande maioria, resistentes a antimicrobianos e que não respondem a vacinas ${ }^{(1-2)}$.

Incidentes envolvendo agentes biológicos, supostamente obtidos através do chamado mercado negro e, até então, produzidos para fins militares ${ }^{(1)}$, vêm atualmente sendo relacionados com a prática do terrorismo e outros atos criminosos. Um evento terrorista é aquele que envolve uma organização ou pessoa que conspira e utiliza meios violentos (como agentes biológicos e tóxicos, bombas e outros) para atingir uma meta política, ideológica ou religiosa. As motivações que levam a tais práticas, bem como os tipos de grupos que as executam, são diversos. Os eventos terroristas nos recentes anos têm sido atribuídos a grupos terroristas da ala esquerda, indivíduos ou grupos nacionalistas-separatistas, grupos ad hoc comprometidos com vingança e, também, grupos religiosos ligados a seitas violentas ou profecias apocalípticas ${ }^{(2)}$.

Segundo informações obtidas da base de dados do Monterey Institute of International Studies da cidade de Monterey, Califórnia, EUA, cinqüenta e cinco eventos relacionados ao terrorismo biológico e químico ocorreram no mundo, em um período de quarenta anos (1960-1999). Embora eventos terroristas tenham sido raros, a freqüência de tais incidentes (principalmente aqueles realizados por "brincadeiras") voltados para organizações, populações civis e símbolos arquitetônicos têm aumentado abruptamente nos últimos anos ${ }^{(2)}$.

Dos ataques terroristas com agentes biológicos, somente um atingiu um grande número de vítimas ao utilizar, em 1984, a bactéria Salmonella typhimurium, no restaurante Dalles, em Oregon, EUA. Esse evento resultou em setecentos e cinqüenta e um casos de intoxicação alimentar, todos não fatais. Em 1995, o grupo terrorista Aum Shinrikyo, utilizando o gás sarin, matou doze pessoas no metrô de Tokyo ${ }^{(2)}$.

Acreditava-se, até os incidentes ocorridos nos EUA, envolvendo a bactéria $B$. anthracis, que a necessidade de tecnologias sofisticadas, de alto custo $e$ de mão-de-obra altamente especializada para a produção, armazenamento e transporte de agentes biológicos e toxinas, representassem barreiras técnicas que imporiam 
limites aos atos terroristas com numerosas vítimas. Porém, esses ataques vêm indicar que nem fatores técnicos, como os tratados para o controle de armas, nem a repugnância moral associada ao uso de armas biológicas, deterão a utilização desses agentes como arma de destruição em massa ${ }^{(1)}$. Um ataque em que é utilizado armas biológicas, ao contrário de um ataque militar convencional, pode ocorrer como um evento oculto no qual as pessoas estão alheias à própria exposição. Além disso, ele pode não ser óbvio por dias e semanas. Assim, epidemias podem ser iniciadas, adoecendo ou matando um grande número de civis, antes mesmo que o diagnóstico correto da doença seja feito pelos serviços de saúde. A falta de familiaridade da maioria dos profissionais da saúde em relação a algumas doenças como a tularemia, a varíola, a praga, o ebola e mesmo o anthrax dificulta e acaba atrasando o diagnóstico precoce e a implementação de medidas de controle ${ }^{(3-4)}$.

Nos dias de hoje, a disponibilidade de recursos e serviços cada vez mais modernos, como o transporte aéreo, podem facilitar a propagação rápida de algumas doenças (febre hemorrágica ebola, praga e varíola) a todos os países do mundo, mesmo aqueles não envolvidos com guerra ou aqueles não visados pelo terrorismo, como é o caso do Brasil. O bioterrorismo era uma realidade distante. Hoje, nenhum país está livre de suas graves conseqüências.

Reconhecendo antigas doenças

Muitos agentes biológicos com potencial reconhecido para o uso em bioterrorismo são conhecidos em nosso meio, embora alguns não sejam usuais. O CDC$P$ define três categorias de agentes biológicos ( $A, B$ e $C$ ) e descreve agentes químicos que causariam grandes impactos na saúde pública se usados como armas, em guerras biológicas e químicas ${ }^{(5-6)}$. Neste artigo, serão discutidos apenas os agentes biológicos e as doenças que fazem parte da categoria $A$ (por facilidade de disseminação ou transmissão dos agentes): Bacillus anthracis (anthrax), Clostridium botulinum toxin (botulismo), Yersinia pestis (praga), varíola major (varíola), Francisella tularensis (tularemia), febre hemorrágica viral (ebola) $^{(7)}$.

A. Anthrax - B. anthracis

Anthrax (palavra originada do grego que significa carvão) é uma doença infecciosa aguda, também conhecida como carbúnculo por causar lesão cutânea negra $^{(8)}$. É causada pela bactéria Bacillus anthracis, um bacilo gram-positivo, aeróbio e esporulado, muito resistente, capaz de sobreviver por muitos anos no meio ambiente ${ }^{(3)}$. Ocorre comumente em rebanhos de mamíferos como gados e ovelhas, que adquirem esporos ingerindo solo contaminado. Ocasionalmente, humanos podem ser infectados através do contato com a pele, ingestão e inalação de esporos do $B$. anthracis de animais infectados, produtos animais (pêlo) e materiais contaminados ${ }^{(3,8-11)}$. A transmissão de pessoa a pessoa da doença inalatória não ocorre. A exposição direta às secreções das lesões do anthrax cutâneo pode resultar em infecção cutânea secundária $^{(3)}$.

Em humanos, a infecção pode ocorrer de três formas: pulmonar, cutânea e gastrointestinal, dependendo de como a doença foi contraída. A forma pulmonar está associada ao bioterrorismo devido à facilidade com que a população pode ser exposta ao aerossol contendo esporos da bactéria ${ }^{(8-11)}$. O período de incubação varia de um dia a oito semanas, com aparecimento dos sintomas iniciais em torno de sete dias após a exposição ${ }^{(11-12)}$.

A infecção pulmonar apresenta duas fases clínicas. Inicialmente, sintomas inespecíficos como febre, dispnéia, tosse, cefaléia, vômitos, fraqueza, dor abdominal e torácica podem ser confundidos com os sintomas de uma gripe. A segunda fase inicia-se, abruptamente, com febre alta, insuficiência respiratória grave, choque e morte. Metade dos pacientes desenvolvem meningite hemorrágica com meningismo, delírios e obnubilação e, nesse caso, a morte ocorre em horas. O anthrax inalatório é freqüentemente fatal ${ }^{(3,8-12)}$.

A forma cutânea é adquirida na maioria dos casos (95\%), quando existe alguma lesão de continuidade na pele. A infecção inicia-se com uma pápula pruriginosa similar a uma picada de inseto. Dentro de um a dois dias converte-se em uma vesícula de um a três milímetros com secreção clara ou serosanguinolenta, que progride para uma lesão de, aproximadamente, um a três centímetros, necrótica ao centro, evoluindo para uma escara seca com resolução em uma a duas semanas ${ }^{(8-12)}$, não deixando cicatriz.

A infecção gastrointestinal é adquirida quando se consome alimento contaminado com esporos e é caracterizada por inflamação aguda do trato gastrointestinal. Inicia-se com sintomas inespecíficos como náusea, anorexia, vômito, febre, seguidos de dor 
abdominal, hematêmese e diarréia grave. Esses sintomas progridem rapidamente para diarréia sanguinolenta, abdome agudo e sepse. Normalmente, pode levar o indivíduo à morte ${ }^{(3,9)}$.

O diagnóstico pode ser realizado através de testes laboratoriais rápidos como antigen-capture enzyme-linked immunosorbent (ELISA), hemocultura, gram e cultura vesicular, no caso de antraz cutâneo ${ }^{(11-12)}$. Os antibióticos de escolha para o tratamento e profilaxia dessa infecção são a Penicilina G, a Doxiciclina e a Ciprofloxacina, administrados durante 60 dias ${ }^{(9,11-12)}$. Como medida preventiva é indicada a profilaxia com antimicrobianos (até que a exposição seja confirmada, quando, então, o tratamento continua por oito semanas) e a imunização com três doses da vacina (anthrax inativado), em intervalos de quinze dias ${ }^{(3)}$.

\section{B. Tularemia - Francisella tularensis}

A tuleramia é uma zoonose bacteriana, predominantemente rural, que, ocasionalmente, acomete o homem. É encontrada em toda a América do Norte, algumas regiões da África do Norte, Europa e Ásia ${ }^{(11-13)}$. É causada pela bactéria Francisella tularensis, bacilo aeróbio, gram-negativo, não esporulado e altamente resistente, capaz de sobreviver por semanas sob baixas temperaturas em água, solo úmido, feno, palha ou carcaça de animal em decomposição. Essa espécie é dividida em duas subespécies: F. tularensis biovar tularensis (tipo A), mais comumente encontrada na América do Norte, altamente virulenta em animais e humanos e $F$. tularensis biovar palaearctica (tipo B), de baixa virulência, mas causadora de todos os casos de tuleremia humana na Europa e Ásia ${ }^{(11-13)}$. É considerada uma arma biológica potente, por ser altamente virulenta, de fácil disseminação e com grande capacidade de causar doença e morte ${ }^{(13)}$.

Os reservatórios naturais dessa bactéria são pequenos roedores (coelho, castor e outros), pássaros selvagens, além de alguns anfíbios e peixes. Os vetores são moscas hematófagas, carrapatos (inclusive de cachorros) e piolhos de coelhos ${ }^{(11)}$.

A infecção humana pode ocorrer por ingestão de água, carne ou solo contaminado; picada de moscas e carrapatos infectados; manipulação de tecidos e fluidos de animais infectados; inoculação pelos olhos; inalação de ar, poeira e pólen contaminado; contato direto com a bactéria através da abertura de placa de cultura ${ }^{(11-13)}$. Não tem sido relatada a transmissão de uma pessoa a outra. $O$ período de incubação varia de um a quatorze dias. Em média, a doença febril não específica pode ter início entre o terceiro e quinto dia, após exposição(11-12).

A tularemia apresenta-se em seis formas clássicas: ulceroglandular, glandular, oculoglandular, orofaringeana, pulmonar e tifoidal ou séptica ${ }^{(11-12)}$. Os sintomas clínicos iniciais são febre, calafrios, linfadenopatia, mal-estar generalizado, mialgia, diarréia, fadiga, anorexia, lesões cutâneas papulares ou vesicopapulares. Após o envolvimento de nódulos linfáticos regionais, órgãos como pulmão, fígado, rins e outros nódulos linfáticos podem ser acometidos. Com a progressão dos sintomas e sem o devido tratamento, ocorrerão a falência respiratória, choque e morte ${ }^{(11)}$.

O diagnóstico ${ }^{(11-12)}$ pode ser feito através de cultura e fluorescência direta do exudato da ferida e sangue, ELISA e Polimerase Chain Reaction (PCR). A melhor forma de prevenção da doença é a não exposição ao agente etiológico em seu ambiente natural. A vacina derivada da cepa não virulenta (tipo B) tem sido utilizada para proteger pessoas que trabalham diretamente com a bactéria em laboratórios. Com o tratamento adequado, a taxa de mortalidade, nos EUA, tem sido em torno de $2 \%{ }^{(12)}$. O tratamento é feito com antibióticos como a estreptomicina e a gentamicina, por até dez dias. Outros antibióticos como os macrolídeos, cloranfenicol e as fluoroquinolonas têm sido usados com sucesso no tratamento da tularemia ${ }^{(13)}$.

\section{Peste pulmonar - Yersinia pestis}

É uma doença infecciosa que acomete animais e seres humanos, causada pela bactéria Yersínia pestis, um bastonete aeróbio, gram-negativo, não esporulado, que tem como hospedeiros naturais algumas espécies de roedores. Encontrada em muitas regiões do mundo (Canadá, Europa, EUA, África, Ásia e América do Sul), é transmitida ao homem por pulgas infectadas (vetores da doença), resultando em infecções linfáticas e sangüíneas (peste bubônica e séptica) ${ }^{(3)}$. Essa doença tem tido profundo impacto na história da humanidade, desde o ano de 541 a.C., quando a primeira pandemia de praga foi iniciada no Egito.

Um surto relacionado ao bioterrorismo é feito através do ar, por dispersão de aerossóis, causando uma variante da doença, a peste pulmonar. Quando a Y. pestis infecta os pulmões, os primeiros sinais e sintomas são 
febre, dor de cabeça, fraqueza, muco pulmonar purulento ou serosanguinolento. A broncopneumonia agrava-se dentro de dois a quatro dias, podendo causar choque séptico e, não havendo tratamento adequado e rápido, morte. A transmissão de pessoa a pessoa ocorre através de gotículas de saliva e secreções nasais ${ }^{(3,9)}$. 0 diagnóstico pode ser feito através de dados clínicos, epidemiológicos e laboratoriais como testes sorológicos (prova de aglutinação e imunofluorescência). No caso da peste pulmonar é realizada a cultura de secreções orofaríngeas $^{(3,9)}$.

Os antibióticos recomendados para o tratamento são as estreptomicinas, tetraciclinas e o cloranfenicol. A antibioticoprofilaxia, por sete dias, é recomendada aos contatos $^{(9)}$. A vacina contra a peste bubônica existe, mas não tem sido comprovada sua eficácia para a forma pulmonar da doença. A mortalidade dos casos não tratados da praga pulmonar é de $100 \%{ }^{(14)}$.

\section{Botulismo - Clostridium botulinum}

O botulismo é uma doença músculo-paralisante, não transmitida de pessoa a pessoa. É causada pela neurotoxina produzida pelo Clostridium botulinum, uma bactéria gram-positiva, anaeróbia e esporulada. Casos de botulismo são raros e resultam tipicamente da absorção da toxina pela pele lesada e mucosa do trato gastrointestinal, quando alimentos contaminados são ingeridos, adoecendo o indivíduo em poucas horas. A forma inalatória do botulismo é também possível e está relacionada ao bioterrorismo ${ }^{(15)}$.

O botulismo alimentar é acompanhado de sintomas gastrointestinais como náuseas, vômitos, boca seca, além de visão dupla ou embaçada, ptose palpebrar, dificuldade para deglutir e paralisia muscular (que se inicia primeiro nos ombros, braços, coxas e panturrilhas). Aparece, geralmente, dentro de doze a trinta e seis horas. A paralisia dos músculos respiratórios leva à morte caso não seja implementado, a tempo, um suporte respiratório ${ }^{(3,9,15)}$. A administração da antitoxina, precocemente, durante o curso da doença é efetiva na redução da severidade dos sintomas do botulismo ${ }^{(3)}$.

\section{E. Varíola - vírus da varíola}

Há evidências de que os primeiros casos da doença surgiram antes da era cristã ${ }^{(12)}$. A varíola foi erradicada em todo o mundo, em $1977^{(9,16)}$. A doença é causada por um vírus pertencente ao grupo dos poxvírus. São muito resistentes se mantidos sob baixas temperaturas, podendo permanecer viáveis nas crostas e secreções das lesões, em roupas e superfícies, por vários anos. No entanto, são pouco resistentes ao calor ${ }^{(11)}$.

É transmitido pelo contato direto entre as pessoas, através das secreções orofaríngeas e lesões cutâneas de pessoas infectadas ou por aerossol ${ }^{(9,16)}$. A varíola é mais infectante, durante a primeira semana, quando um grande número de vírus está presente na saliva, mas existe risco de se contraí-la até que todas as crostas tenham caído ${ }^{(7,9)}$. Os sintomas iniciais começam a aparecer em torno de doze dias após a exposição e incluem febre alta, fadiga, dor de cabeça e nuca, além de dor abdominal e delírios. Dentro de dois a três dias, após o início dos primeiros sintomas, uma erupção característica aparece primeiro na mucosa da boca e faringe, depois face, tronco, braços e pernas. As lesões inicialmente são planas e avermelhadas, transformando-se em lesões vesiculares cheias de pus que em duas semanas, secam, criando crostas, que vão se desprendendo à medida que o indivíduo vai evoluindo para a cura. A maioria dos pacientes com varíola recupera-se, mas em $30 \%$ dos casos ocorre a morte $^{(3,9,16)}$.

O tratamento da varíola é feito através de suporte hídrico, medicamentos para controle da febre e dor, não havendo medicamentos específicos. Antibióticos podem vir a ser usados caso ocorram infecções secundárias ${ }^{(9,16)}$. A vacinação rotineira contra varíola foi suspensa em 1972. Não se sabe com precisão o nível de imunidade entre as pessoas vacinadas. Acredita-se que os efeitos da imunização durem de três a cinco anos, assim, pessoas anteriormente vacinadas estão susceptíveis à doença ${ }^{(16)}$. Após exposição ao vírus da varíola, a vacina é indicada para diminuir a severidade da doença ou preveni-la, se aplicada em um prazo de quatro dias ${ }^{(9)}$.

\section{F. Febre hemorrágica ebola- vírus Ebola}

A febre hemorrágica ebola é doença grave, freqüentemente fatal em humanos e em primatas. A doença tem se manifestado esporadicamente desde seu reconhecimento em 1976, na África, onde casos confirmados foram reportados no Congo, Gabão, Costa de Ivory e Uganda. A doença é causada pela infecção com o vírus Ebola, um dos componentes da família de vírus RNA, chamado Filoviridae ${ }^{(17)}$. Três das quatro espécies de vírus Ebola identificados causam doença em 
humanos: Ebola-Zaire, Ebola-Sudan e Ebola-Ivory Coast. A quarta espécie, o Ebola-Reston, tem causado doença em primatas, mas não há casos relatados em humanos. O reservatório natural do vírus Ebola e a existência de vetores artrópodes não são ainda bem conhecidos. Pesquisadores acreditam, porém, baseados em outras viroses, que ele tenha como abrigo um hospedeiro animal que é nativo do Continente Africano ${ }^{(17)}$.

O vírus é transmitido durante o contato direto pessoa a pessoa, com cadáveres e, indiretamente, através de materiais contaminados com fluidos corporais infectados como sangue, urina, fezes, saliva, secreções da orofaringe e esperma. Por essa razão, os familiares e os profissionais de saúde correm maior risco de se infectarem. A transmissão por via aérea não foi observada em epidemias humanas, mas o assunto é ainda controverso. A porta de entrada do vírus são as mucosas e pele com lesões de continuidade ${ }^{(17-18)}$.

Os sinais e sintomas da febre hemorrágica ebola não são os mesmos para todos os pacientes. Os sintomas mais freqüentes que têm sido reportados nos casos conhecidos, incluem febre alta, dor de cabeça, mialgia, dor no estômago, fadiga e diarréia. Alguns pacientes apresentaram ainda dor de garganta, erupção cutânea, petéquias, olhos vermelhos e edemaciados, hematêmese, melenas e epistaxes. Dentro de uma semana, o paciente pode apresentar dor no peito, cegueira, severas hemorragias, anúria, hipotensão e choque seguido de morte. Seu estágio inicial pode ser confundido com febre tifóide e malária ${ }^{(18)}$.

Não existe vacina e nem tratamento específico para a febre hemorrágica ebola. O paciente recebe suporte hídrico com reposição de eletrólitos, oxigenoterapia, antibióticos para infecções secundárias, transfusões, etc. O diagnóstico pode ser feito pelo teste ELISA, IgG ELISA, $\mathrm{PCR}$ e isolamento do vírus, no início dos sintomas ${ }^{(17-18)}$.

Práticas de controle de infecção para o cuidado de pacientes dentro do ambiente hospitalar

Rotineiramente, para a assistência a todos os pacientes hospitalizados, utilizam-se medidas de precauções-padrão $^{(4)}$ que incluem a lavagem das mãos (água, sabão e álcool glicerinado a 70\%); o uso de equipamentos de proteção individual (EPI) como luvas, máscara, gorro, avental e óculos protetores; a vacinação; a prevenção de acidentes perfurocortantes; o uso de curativos oclusivos para feridas exudativas e outros. São medidas empregadas para reduzir o risco de transmissão de microorganismos, cujas fontes de infecção podem ser ou não conhecidas, para todo e qualquer paciente hospitalizado e para minimizar o risco ocupacional dos profissionais que manipulam materiais contaminados ou sob suspeita de contaminação com qualquer tipo de fluidos corporais $^{(19)}$. Em algumas doenças infecto-contagiosas, essas medidas são empregadas juntamente com precauções adicionais específicas para a transmissão por contato, ar e perdigotos.

Para o cuidado de pacientes sintomáticos com suspeita ou confirmação de infecção associada ao $B$. anthracis, o CDC-P, é recomendado o emprego de precauções-padrão para o controle de infecções ${ }^{(3)}$ :

- na admissão, o paciente deve ter sua pele descontaminada mediante banho de imersão com água e sabão. Pertences e roupas do paciente, que possam estar contaminados com esporos, devem ser manipulados com cautela, utilizando-se EPI. Eles devem ser acondicionados em sacos plásticos vedados, autoclavados e/ou incinerados:

- é desnecessário o isolamento do paciente em quarto privativo uma vez que o bacilo não é transmitido através do ar e perdigotos;

- utilização de luvas e avental no manuseio dos pacientes com a forma cutânea da doença, incluindo erupções cutâneas e lesões, e máscaras e óculos protetores quando houver possibilidade de respingos ou pulverização de fluidos corporais no ambiente;

- lavagem das mãos dos profissionais antes e após calçar luvas. Orientação de pacientes, acompanhantes e visitantes para a lavagem das mãos e redução no manuseio e movimentação de roupas, evitando contato com outros pacientes;

- uso de precauções-padrão para a movimentação e transporte do paciente;

- superfícies de móveis e equipamentos do quarto devem ser submetidos a limpeza concorrente padrão, podendo ser usada solução de hipoclorito a $0,05 \%$. Em casos de contaminação, do piso, com sangue e outros fluidos, solução de hipoclorito a $0,5 \%$ deve ser utilizada; - utilização de estetoscópios, termômetros e esfignomanômetros exclusivos do paciente. Executar a limpeza e desinfecção dos mesmos rotineiramente;

- recomenda-se a autoclavação de instrumentais e equipamentos que entrem em contato com tecidos estéreis e fluidos corporais. Talheres e utensílios devem ser lavados com detergente, água quente e hipoclorito a 0,05\% para 
descontaminação ou processados em máquinas, que utilizam água quente;

- após óbito, os cuidados com o preparo do corpo são os mesmos recomendados para pacientes portadores de doenças infecto-contagiosas. Deve-se utilizar todos os equipamentos de proteção individual durante o preparo.

Para o cuidado de pacientes sintomáticos, com suspeita ou confirmação de tularemia cutânea e pulmonar, bem como para pacientes com suspeita ou confirmação de botulismo, a recomendação do CDC-P é que sejam utilizadas medidas de precauções-padrão durante toda a internação dos pacientes, no hospital ${ }^{(3)}$. Como não ocorre transmissão de pessoa a pessoa, em nenhuma das duas doenças, não há necessidade de isolamento respiratório, quarto privativo e sistema especial de ar. A limpeza, desinfecção e esterilização de ambiente, equipamentos, instrumentais, bem como o transporte do paciente, manipulação de roupas devem ser feitos utilizando as precauções-padrão recomendadas para todo e qualquer paciente hospitalizado.

Para o cuidado de pacientes com suspeita ou confirmação de infecção por Yersinia pestis, principalmente para a variante peste pulmonar, o CDC-P recomenda que medidas de precauções para transmissão por perdigotos devam ser utilizadas em conjunto com as precauções-padrão ${ }^{(3)}$ :

- utilização de quarto privativo. Em caso de epidemias pode-se fazer uma "coorte" de pacientes em um mesmo ambiente, mantendo uma distância de 1 metro entre um leito e outro;

- utilização de máscara "tipo cirúrgica" para o contato com o paciente a uma distância menor que um metro. $O$ microorganismo (maior $5 \mu$ ) pode ser veiculado pela tosse, fala, espirro e em procedimentos envolvendo o trato respiratório (aspiração e broncoscopia);

- precauções com a transmissão, via perdigotos, devem ser mantidas até completar setenta e duas horas de antibioticoterapia;

- movimentação e transporte do paciente devem ser limitados. O paciente deve estar utilizando máscara cirúrgica;

- medidas de precauções-padrão e aquelas referentes à transmissão via perdigotos devem ser aplicadas para o cuidado com o corpo após a morte do paciente.

Para pacientes com suspeita ou confirmação de varíola, precauções de contato e via ar são recomendadas pelo CDC-P e devem ser utilizadas em adição às precauções-padrão ${ }^{(3)}$ :

- quarto isolado, com sistema de ar especial (microorganismo menor que $5 \mu$ ), com seis a doze trocas de ar por hora, mantendo a pressão negativa em relação ao corredor e áreas adjacentes. Monitorar o sistema de filtro de ar. Portas devem ser mantidas constantemente fechadas;

- uso de máscara tipo cirúrgica ou com filtro HEPA (highefficiency particulate air respirator), para entrada no quarto e os outros EPI;

- lavagem das mãos com água e sabão e aplicação de álcool glicerinado a $70 \%$;

- a movimentação e transporte do paciente devem ser limitadas. A enfermagem deve fazê-lo utilizando precauções-padrão, de contato e de ar. O paciente deve usar máscara;

- equipamentos devem ser de uso exclusivo do paciente. Precauções de contato devem ser empregadas pelos profissionais para a limpeza, desinfecção e esterilização de superfícies e equipamentos potencialmente contaminados. Precauções de contato e ar devem ser utilizadas para o cuidado com o corpo após a morte.

Para o cuidado dos casos suspeitos ou confirmados de febre hemorrágica Ebola, o CDC-P recomenda o emprego de precauções-padrão juntamente com precauções de contato ${ }^{(20)}$ :

- isolamento do paciente em quarto privativo, com sistema de ar condicionado. Caso não seja possível as janelas devem ter telas-mosquiteiro;

- uso de EPI. As luvas devem ser duplas, aventais de plástico recobrindo capotes, máscaras com filtro HEPA e botas de borracha;

- termômetros, estetoscópios e aparelhos de pressão devem ser exclusivos do paciente. Entre cada uso devese proceder à limpeza e fricção com álcool 70\%, durante trinta segundos, por três vezes;

- limitar o uso de procedimentos invasivos e medicações injetáveis e o número de profissionais e visitantes no quarto. A enfermagem deve orientar visitantes e familiares quanto ao uso de roupas de proteção e a técnica de lavagem das mãos;

- para limpeza de equipamentos e superfícies de móveis deve-se usar água e sabão ou detergentes, seguidos do uso de solução clorada a 0,05\% (diluição 1:100). Para respingos de fluidos corporais no chão deve-se usar solução clorada a 0,5\% (diluição 1:10); 
- utensílios como talheres, copos e outros devem preferencialmente ser descartáveis, ou caso contrário, devem ser imersos em solução clorada a 0,05\%. Materiais descartáveis devem ser incinerados;

- cuidado especial deve ser tomado pelo profissional a fim de se evitar a autocontaminação durante a retirada dos EPI: lavar com água e sabão as luvas externas e depois esfregá-las com solução clorada (1:100) por um minuto; desinfetar o avental de plástico e as botas de borracha usando solução clorada (1:100); remover o par de luvas externas e descartá-las em recipiente adequado; fora do isolamento retirar o avental plástico, o capote e então lavar o par de luvas internos da mesma forma feita com as luvas externas; retirar os óculos protetores, o gorro e a máscara; as botas devem ser removidas sem contato com a mãos; remover o par de luvas internas descartando em recipiente adequado; lavar as mãos novamente; remover as roupas internas; lavar novamente as mãos antes da saída do quarto de troca;

- roupas de cama e de uso do paciente no hospital devem ser manipuladas com cautela e utilizando EPI; devem ser acondicionadas em sacos identificados, transportadas adequadamente e lavadas como de rotina para qualquer paciente hospitalizado;

- para o cuidado com o corpo após morte devem ser usados todos os equipamentos de proteção individual, inclusive par de luvas duplas, botas de borracha e máscaras com filtro HEPA.

\section{REFERÊNCIAS BIBLIOGRÁFICAS}

1. Center for Civilian Biodefense Studies. Threat of bioterrorism. [online]. [acessado out 2001]. Disponível em: URL: <http://www.hopkins-biodefense.org/pages/center/ threat.html>

2. Tucker JB. Historical trends related to bioterrorism: an empirical analysis. Rev Biomed 1999 julio-septiembre; 10(3):185-93.

3. APIC-Bioterrorism Task Force and CDC-Hospital Infections program Bioterrorism Working Group. Bioterrorism readiness plan: a template for healthcare facilities. [online]. [acessado out 2001]. Disponível em: URL: <http://www.cdc.gov/ncidod/ hip/Bio/bio.htm>

4. Center for Civilian Biodefense Studies. A New Form of Terrorism. [acessado out 2001]. [online]. Disponível em: URL: <http://www.hopkins-biodefense.org/ pages/center/form.html> 5. Center for Civilian Biodefense Studies. Agent Fact Sheet Info. [acessado out 2001]. [online]. Disponível em: URL: <http:/ /www.hopkins-biodefense.org/ pages/agents/agent.html>

6. CDC. Recognition of iilness associated with the intentional release of a biological agent. MMWR 2001; 50(49):893-7.

7. CDC. Agent/Disease. [acessado out 2001]. [online]. Disponível em: URL: <http://www.bt.cdc.gov/Agent/ Agentlist.asp>

\section{CONSIDERAÇÕES FINAIS}

As instituições de saúde e seus profissionais devem estar prontos para lidar eficientemente com as conseqüências da utilização de armas biológicas. Os enfermeiros e sua equipe devem ter a preparação técnicocientífica e emocional para a identificação precoce dos sintomas e susceptibilidade de cada doença. Para isso, é importante que sejam oferecidos aos profissionais a oportunidade de atualização e treinamento, através de acesso a veículos de divulgação científica como cursos, palestras, debates e discussões de artigos envolvendo a temática das doenças infecto-contagiosas e o bioterrorismo, bem como suas medidas de controle.

Hospitais que possuírem um Serviço de Epidemiologia Hospitalar, cujo Programa de Controle de Infecção seja bem estruturado, contando com apoio de um laboratório de microbiologia avançado e profissionais de saúde capacitados e atualizados, não enfrentarão dificuldade para diagnosticar, tratar e controlar os possíveis casos isolados ou mesmo epidemias decorrentes de um ataque bioterrorista. Se por um lado a capacitação técnicocientífica dos profissionais é fundamental para o cuidado adequado aos pacientes, a preparação e apoio emocional são essenciais para minimizar as ansiedades que poderão surgir na enfermagem, no decorrer da assistência, em relação aos riscos potenciais de contaminação e infecção. Estamos preparados?

8. Center for Civilian Biodefense Studies. Agents/Anthrax. [acessado out 2001]. [online]. Disponível em: URL: <http:// www.hopkins-biodefense.org/pages/agents/ agentanthrax.html>

9. CDC. Facts About: Anthrax, Botulism, Pneumonic Plague, and Smallpox. [acessado out 2000]. [online]. Disponível em: URL: <http://www.bt.cdc.gov/DocumentsApp/FactsAbout/ FactsAbout.asp>

10. Pile JC, Malone JD, Eitzen EM, Friedlander AM. Anthrax as a potential biological warfare agent. Arch Intern Med 1998; 158:429-34.

11. Amstrong D, Colten J, organizadores. Infectious Diseases. Philadelphia: Mosby; 2001.

12. Mandell GL, Bennett JE, Dolin R, editors. Principles and practice of infectious diseases. 5 ed. New York: Churchill Livinstone; 2000.

13. Center for Civilian Biodefense Studies. Agents. [acessado out 2001]. [online]. Disponível em: URL: <http://www.hopkinsbiodefense.org/ pages/agents/agenttularemia.html>

14. Center for Civilian Biodefense Studies. Agents. [acessado out 2001]. [online]. Disponível em: URL: <http://www.hopkinsbiodefense.org/ pages/agents/agentplague.html>

15. Center for Civilian Biodefense Studies. Agents. [acessado out 2001]. [online]. Disponível em: URL: <http://www.hopkinsbiodefense.org/ pages/agents/agentbotox..html> 
16. Center for Civilian Biodefense Studies. Agents. [acessado out 2001]. [online] Disponível em: URL: <http://www.hopkinsbiodefense.org/ pages/agents/agentsmallpox.html>

17. Center for Disease Control. Disease. Fact Sheets: Ebola Hemorragic Fever. [acessado out 2001]. [online]. Disponível em: URL: <http://www.cdc.gov/ncidod/dvrd/spb/mnpages/ dispages/ebola.htm>

18. Camara FP. O vírus ebola e sua infecção. Folha Médica 1995 julho/setembro; 111(1):47-51.

19. Martins MP. Manual de infecção hospitalar: epidemiologia, prevenção e controle. 2 ed. Rio de Janeiro: Medsi; 2001.

20. Centers for Disease Control and Prevention and World Health Organization. Infection Control for Viral Hemorrhagic Fevers in the African Health Care Setting. Atlanta; 1998. 